\title{
Morphology of the larvae of Arrenurus biscissus (O. F. Müller), 1776; A. pugionifer Piersig, 1897 and A. bisulcicodulus George, 1881 (Acari: Parasitengona: Arrenuridae)
}

\author{
A. Zawal
}

Department of Invertebrate Zoology \& Limnology, University of Szczecin, 71-415 Szczecin, Wąska 13, Poland. E-mail: zawal@univ.szczecin.pl

\begin{abstract}
The morphology of the larval stages of Arrenurus biscissus, A. pugionifer and A. bisulcicodulus is described. The three species belong to the subgenus Micruracarus and share several characters. The larvae of the three species differ in the shape of the dorsal plate, shape of the excretory pore plate, ratio between length of coxal plate median margins, and the numbers of pectinating setae on fifth palpal segment (PV). The larva of $A$. biscissus is very similar to the closely related A. sinuator. Larvae of $A$. pugionifer and A. bisulcicodulus resemble other Micruracarus species (A. bifidicodulus, A. inexploratus, A. integrator).
\end{abstract}

Keywords: Hydrachnidia, Micruracarus, water mites, larvae, morphology

\section{Introduction}

As in other higher taxa of water mites, also the subgeneric classification within Arrenurus is based on adults. Cook (1974) suggests that the Arrenurus subgeneric classification is artificial. Larval characters could prove useful in helping to solve these problems. A study of this kind begins with descriptions of the larval morphology of as many species as possible. Descriptions of the larvae of several species within the genus can be found in papers of Koenike (1908), Lundblad (1927, 1930), Münchberg (1936), Sparing (1959), Imamura and Mitchell (1967), Prasad and Cook (1972), Stechmann (1977), Smith I. M. (1978), Vainstain (1980), Cichocka (1980), Tuzovsky (1987), Smith B. P. (1990), Smith and Cook (1991), Martin 2000, Böttger and Martin (2003) and Zawal (2006a, b, c, d, e, 2007).

The present paper is aimed at describing A. biscissus, A. pugionifer and A. bisulcicodulus, which belong to the subgenus Micruracarus, and highlights the characters that allow us to differentiate between the three species; and compare those characters with the earlier descriptions of other Arrenurus species.

\section{Materials and methods}

The descriptions are based on larvae hatched from eggs laid by females caught in the field in several sites located in Poland (see below). Until egg laying, each female was held in a separate $100 \mathrm{~cm}^{3}$ container filled with $20-24^{\circ} \mathrm{C}$ water and subsequently fixed in Wilson's liquid (Zawal 2006c). The eggs were held until hatching, under identical conditions. $48 \mathrm{~h}$ after hatching larvae were mounted in Hoyer's medium; the $48 \mathrm{~h}$ period being necessary for the larvae to became fully sclerotised.

Larval morphology of A. biscissus, A. pugionifer and A. bisulcicodulus was described based on larvae hatched from eggs laid by a single female of each of the species. The habitat characteristics of the collecting sites and sampling data as follows: A. biscissus: small lake with sandy bottom in Poznań, 15 May 2004, A. pugionifer: lake with muddy bottom in an alder-forest near Zgnitek, Międzychód district, 16 May 2004, A. bisulcicodulus: lowland peatbog Krępskie Bagno near Krępsko, among sedges, Goleniów district, 2 May 2003). The mounts (A. biscissus: Nos 136E, 136Ea; $A$. pugionifer: Nos 52E, 52Ea; A. bisulcicodulus: Nos $822,822 \mathrm{a}$ ) are stored at the Department of Invertebrate Zoology and Limnology, University of Szczecin. Larval body parts were measured on the progeny of three females of A. biscissus, one female of A. pugionifer, and 10 females of A.bisulcicodulus. The females were collected from various habitats, in order to document a relatively wide range of individual variability.

Drawings were prepared with a drawing attachment to a Nikon ECLIPSE80i microscope. It is very difficult to adequately represent the arrangement of the secon- 
dary setae as they are frequently barely visible. For this reason, those setae bearing secondary ones were drawn as they were spotted, at least in one mount. Consequently, all the setae drawn appear to bear secondary setae, as they in fact do. On the other hand, the lack of secondary setae on smooth primary ones could have been caused by overlooking them on a mounted specimen. The setal terminology follows Prasad and Cook (1972), with modification by Zawal (2006a). The metric characters are reported with their ranges, mean values, and standard deviations. The leg segments were measured from their distal margins. In this paper the following abbreviation are used: $\mathrm{Cp}$ - coxal plate, Exp - excretory pore, Expp - excretory pore plate.

\section{Results}

\section{Arrenurus biscissus}

The oval dorsal plate is widest in the middle of its length and distinctly narrows in the posterior and the anterior parts. The anterior margin is almost straight and the posterior margin is rounded. The anterior-lateral incisions are very small, almost invisible, with obtuse angles, and reach to about one-fifth of the plate width and one-seventh of its length. The $\mathrm{Lpl}$ seta is tripartite; the remaining setae smooth (Fig. 1B).

Median margins of the $\mathrm{CpI}$ are distinctly the longest, followed by CpII and CpIII (Fig.1A). The ratios of $\mathrm{CpI} / \mathrm{CpII} / \mathrm{CpIII}$ are 3.9/2.3/1 respectively (Table 1). All seatae on the coxal plates are bipectinate (Fig. 1A). The distance $\mathrm{C} 1-\mathrm{CpI}$ median margin reaches to about $3 / 4$ the $\mathrm{C} 4-\mathrm{CxpIII}$ median margin. The $\mathrm{C} 1-\mathrm{C} 2$ distance is long (Table 1, Fig. 1A).

The Expp is pentangonal-shaped with a characteristic process on the posterior part which includes the Exp. The Exp is situated distintly posterior to the middle of the shield and posterior to the E2 setae (Table 1, Fig. 1C).

In shape and sizes pedipalps resemble those of other Arrenurus species. The PIII1 seta is thick and bipectinate. The PV4 and PV5 setae are bipectinate, the PV4 seta long and thin and PV5 thicker and shorter (Fig. 1D).

The first segment of the chelicerae has the form of an elongated and slightly curved cylinder with margins parallel to each other (Fig. 1E).

The proportions of the segments are more or less the same on each leg. The distinctly shortest trochanter constitutes about $2 / 3$ of the length of the femur, the genu is slightly shorter than the femur, the tibia is 1.5 times longer and the tarsus twice as long (Table 2).
The IGe3, ITi3, IIGe3, IIGe4 IITi3, IIIGe3, IIIGe4, IIITi3 and IIITi4 setae are thick and bipectinate. The ITi8 seta is long and thin; IITi10 is pectinate and lies near the centre of the tibia (Fig. 1F, G, H).

\section{Arrenurus pugionifer}

The dorsal plate is oval, widest in the middle of its length and narrowing distinctly to the front; the posterior margin is pointed. The anterior-lateral incisions are visible but rather small, their angles almost straight, reach about one-sixth of the length and one-third of the width of the plate. The Lpl seta is tripartite, the remaining setae are smooth and thin (Fig. 2B).

The CpII median margin is the shortest. The ratio of $\mathrm{CpI} / \mathrm{CpII} / \mathrm{CpIII}$ median margins is 2.1/1/1.6 (Table 1), respectively. All setae on the coxal plates and the V3 setae are bipectinate (Fig. 2). The distance $\mathrm{C} 1-\mathrm{CpI}$ median margin reaches about $2 / 3$ the distance $\mathrm{C} 4-\mathrm{CpIII}$ median margin. The $\mathrm{C} 1-\mathrm{C} 2$ distance is rather short (Table 1, Fig. 2A).

The Expp is almost rounded, slightly wider than long, with the anterior margin slightly convex and posterior one pointed, with a characteristic process below. The Exp is situated posterior to the centre of the plate and beneath the E2 setae (Fig. 2C).

The PIII1 seta is bipectinate, and the PV5 is pectinate (Fig. 2D).

The first segment of the chelicerae is elongated with slightly bent margins parallel to each other (Fig. 2E).

The segments of the limbs are slightly shorter than in A. biscisus, however the proportions are similar (Table 2). The IITi8 seta is thick, short and bipectinate, the IITi10 seta is short and pectinate and lies near the centre of tibia, the IIITi10 is bipectinate and lies posterior to the centre of the tibia (Fig. 2F, G, H).

\section{Arrenurus bisulcicodulus}

The dorsal plate is egg-shaped, widest at mid-length with the anterior margin slightly curved and the posterior one rounded. The anterior-lateral incisions are fairly small with slightly obtuse angles, reaching about one-sixth of the length of the plate and one-quarter of its width. The Lpl setae are tripartite and the remaining ones smooth (Fig. 3B).

The $\mathrm{CpI}$ median margins are the longest, followed by CpIII; the shortest are those of the CpII. The ratio of $\mathrm{CpI} / \mathrm{CpII} / \mathrm{CpIII}$ is $2.1 / 1 / 1.3$ respectively (Table 1 ). All the setae on the coxal plates are smooth (Fig. 3). The distance $\mathrm{C} 1-\mathrm{CpI}$ median margin reaches about $2 / 3$ the distance C4-CpIII median margin. The C1-C2 distance is fairly short (Table 1, Fig. 3A). 
Table 1. Dimensions (in ųm) of individual body parts

\begin{tabular}{|c|c|c|c|c|c|c|c|c|c|}
\hline & \multicolumn{3}{|c|}{ A. biscissus $(\mathrm{n}=10)$} & \multicolumn{3}{|c|}{ A. pugionifer $(\mathrm{n}=5)$} & \multicolumn{3}{|c|}{ A. bisulcicodulus $(\mathrm{n}=10)$} \\
\hline & range & mean $\frac{s}{d}$ & $\begin{array}{l}\text { standard } \\
\text { deviation }\end{array}$ & range & mean & $\begin{array}{l}\text { standard } \\
\text { deviation }\end{array}$ & range & mean & $\begin{array}{l}\text { standard } \\
\text { deviation }\end{array}$ \\
\hline length & \multicolumn{2}{|c|}{$258-282270.0$} & 8.432 & \multicolumn{2}{|c|}{$250-274259.8$} & 6.292 & \multicolumn{2}{|c|}{$220-230225.0$} & 3.68 \\
\hline width & \multicolumn{2}{|c|}{$228-252237.4$} & 6.742 & \multicolumn{2}{|c|}{$234-240237.6$} & 2.46 & \multicolumn{2}{|c|}{$184-194188.0$} & 3.27 \\
\hline dorsal plate length & \multicolumn{2}{|c|}{$240-280256.6$} & 13.86 & \multicolumn{2}{|c|}{$232-250244.6$} & 5.252 & \multicolumn{2}{|c|}{$220-224221.4$} & 1.65 \\
\hline dorsal plate width & \multicolumn{2}{|c|}{$220-244229.6$} & 7.47 & \multicolumn{2}{|c|}{$220-224221.2$} & 1.69 & \multicolumn{2}{|c|}{$168-174170.8$} & 2.15 \\
\hline CpI medial margin length & $94-106$ & 96.2 & 3.96 & $75-78$ & 76.3 & 0.86 & $62-67$ & 64.9 & 1.58 \\
\hline CpII medial margin length & $57-58$ & 57.4 & 0.63 & $36-38$ & 36.9 & 0.70 & $31-32$ & 31.4 & 0.39 \\
\hline CpIII medial margin length & $24-26$ & 24.6 & 0.66 & $59-62$ & 60.8 & 1.07 & $38-42$ & 40.8 & 1.25 \\
\hline distance: Mp1-Mp1 & $43-44$ & 43.8 & 0.39 & $45-50$ & 46.8 & 1.47 & $44-46$ & 44.6 & 0.66 \\
\hline distance: Lp1-Lp1 & $64-69$ & 66.9 & 1.37 & $57-68$ & 63.8 & 2.87 & $54-57$ & 55.4 & 0.85 \\
\hline distance: Lp2-Lp2 & $115-118$ & 116.1 & 0.80 & $102-105$ & 103.0 & 1.12 & $94-97$ & 95.7 & 0.67 \\
\hline distance: $\mathrm{Mp2}-\mathrm{Mp} 2$ & $68-70$ & 69.3 & 0.94 & $56-64$ & 60.0 & 2.10 & $52-54$ & 53.1 & 0.86 \\
\hline distance: Mh1-Mp2 & $57-61$ & 59.3 & 1.43 & $63-67$ & 64.6 & 1.20 & $43-48$ & 45.7 & 1.43 \\
\hline distance: Mp1-Lp1 & $8-11$ & 10.0 & 0.94 & $6-10$ & 8.0 & 0.92 & 6-7 & 6.64 & 0.66 \\
\hline distance: Mp1-Lp2 & $38-46$ & 42.7 & 2.21 & $28-37$ & 31.6 & 2.42 & $38-43$ & 39.7 & 1.60 \\
\hline distance: Mp1-Mp2 & $68-70$ & 69.2 & 0.86 & $69-78$ & 72.0 & 2.47 & $70-73$ & 70.7 & 1.20 \\
\hline distance: Mp2-Mh1 & $26-45$ & 39.2 & 5.10 & $15-22$ & 19.0 & 1.85 & $18-27$ & 20.4 & 2.62 \\
\hline distance between $\mathrm{C} 1$ and $\mathrm{CpI}$ median margin & $28-29$ & 28.3 & 0.41 & $22-25$ & 23.8 & 0.91 & $20-22$ & 21.6 & 1.00 \\
\hline distance between $\mathrm{C} 4$ and $\mathrm{CpIII}$ median margin & $41-46$ & 43.1 & 1.33 & $30-32$ & 31.8 & 0.66 & $30-31$ & 30.4 & 0.65 \\
\hline distance between $\mathrm{C} 1$ and $\mathrm{C} 2$ & $57-62$ & 59.8 & 1.45 & $46-52$ & 48.4 & 1.57 & $42-45$ & 43.8 & 0.76 \\
\hline excretory pore plate length & $29-33$ & 30.2 & 1.18 & $32-36$ & 34.3 & 1.33 & $28-30$ & 28.6 & 0.63 \\
\hline excretory pore plate width & $32-36$ & 34.1 & 1.20 & $34-38$ & 37.0 & 1.24 & $30-31$ & 30.1 & 0.56 \\
\hline distance between Exp and Expp posterior margin & $10-11$ & 10.2 & 0.63 & $10-12$ & 10.4 & 0.84 & $9-10$ & 10.0 & 0.57 \\
\hline distance between E1 setae and Expp anterior margin & $6-7$ & 6.2 & 0.51 & $8-10$ & 8.6 & 0.54 & $5-8$ & 6.4 & 1.07 \\
\hline distance between E2 setae and Expp posterior margin & $13-14$ & 13.4 & 0.63 & $13-18$ & 15.0 & 1.35 & $12-16$ & 13.4 & 1.20 \\
\hline PI length & $10-12$ & 10.7 & 0.86 & $8-10$ & 8.6 & 0.63 & $10-13$ & 11.6 & 0.94 \\
\hline PII length & $33-36$ & 34.5 & 0.96 & $30-32$ & 31.0 & 0.66 & $30-34$ & 32.6 & 1.07 \\
\hline PIII length & $35-38$ & 36.9 & 0.96 & $27-31$ & 29.4 & 1.30 & $29-30$ & 30.0 & 0.57 \\
\hline length of PIV claw & $22-27$ & 24.0 & 1.41 & $20-23$ & 21.8 & 1.07 & $20-22$ & 21.1 & 0.67 \\
\hline length of cheliceral segment I & $100-110$ & 104.3 & 2.56 & $89-94$ & 91.2 & 2.60 & $80-86$ & 83.4 & 1.73 \\
\hline length of PV 8 seta & $179-197$ & 191.1 & 5.75 & $162-169$ & 165.4 & 2.20 & $138-141$ & 138.6 & 1.12 \\
\hline
\end{tabular}

The width of the oval excretory pore plate is almost equal to its length. The Exp lies posterior to the centre of the plate and beneath E2 setae (Fig. 3C).

The pedipalps resemble those of A. pugionifer. The PIII1 seta is smooth. The PV5 seta is pectinate and the PV8 bipectinate (Fig. 3D).

The first segment of the chelicerae has the form of a bent and elongated cylinder (Fig. 3E), slightly narrowing to the front.
The dimensions of the different segments of the legs are slightly shorter than those found in A. biscisus, however their mutual proportions are more or less the same (Table 2). The ITi8 is short, IITi10 and IIITi10 are smooth, short and are located about $2 / 3$ of the length of the tibia. On the tarsus of leg pair III, A. bisulcicodulus has one seta more than other species of the genus Arrenurus. It is marked as IIITa8 (Fig. 3F, $\mathrm{G}, \mathrm{H})$. 
Table 2. Dimensions (in ųm) of leg segments

\begin{tabular}{|c|c|c|c|c|c|c|c|c|c|c|c|}
\hline \multirow{5}{*}{ 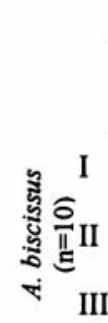 } & \multicolumn{2}{|c|}{ trochanter } & \multicolumn{2}{|c|}{ femur } & \multicolumn{2}{|c|}{ genu } & \multicolumn{2}{|c|}{ tibia } & \multicolumn{3}{|c|}{ tarsus } \\
\hline & range mean & $\begin{array}{l}\text { standard } \\
\text { deviation }\end{array}$ & range & $\begin{array}{l}\text { standard } \\
\text { deviation }\end{array}$ & ran & $\begin{array}{l}\text { standard } \\
\text { deviation }\end{array}$ & $\mathrm{nar}$ & $\begin{array}{l}\text { standard } \\
\text { deviation }\end{array}$ & range & mean & $\begin{array}{l}\text { standard } \\
\text { deviation }\end{array}$ \\
\hline & $24-2624.8$ & 0.84 & $44-5045.7$ & 1.86 & $46-5248.0$ & 1.92 & $73-8075.0$ & 2.29 & $86-99$ & 88.5 & 4.20 \\
\hline & $31-3231.8$ & 0.34 & $48-5451.6$ & 1.57 & $49-5049.8$ & 0.63 & $78-8480.5$ & 1.78 & $100-112$ & 2106.3 & $3 \quad 3.78$ \\
\hline & I $48-4948.2$ & 0.41 & $48-4948.5$ & 0.41 & $48-5149.9$ & 1.14 & $74-8277.5$ & 2.21 & $104-114$ & 108.4 & $4 \quad 2.48$ \\
\hline I & $24-2624.7$ & 0.70 & $40-4342.0$ & 1.42 & $40-4240.6$ & 0.63 & $58-6059.4$ & 0.66 & $74-76$ & 75.0 & 0.63 \\
\hline & $27-2927.8$ & 0.51 & $42-4442.7$ & 0.77 & $40-4240.4$ & 0.57 & $59-6260.7$ & 0.88 & $80-84$ & 82.1 & 1.20 \\
\hline III & I $34-3835.8$ & 1.30 & $40-4241.0$ & 0.83 & $39-4140.1$ & 0.45 & $60-6261.0$ & 0.63 & $80-85$ & 84.2 & 2.03 \\
\hline I & $22-2725.4$ & 1.31 & $40-42 \quad 40.5$ & 0.67 & $35-3736.1$ & 0.59 & $50-5351.4$ & 0.98 & $68-69$ & 68.5 & 0.41 \\
\hline 递苛 & $26-2928.0$ & 0.75 & $41-4241.4$ & 0.34 & $36-3736.6$ & 0.39 & $53-5553.9$ & 0.77 & $71-76$ & 73.8 & 1.64 \\
\hline III & I $35-3635.7$ & 0.41 & $40-4240.6$ & 0.63 & $37-3837.4$ & 0.39 & $54-5655.2$ & 0.84 & $75-76$ & 75.9 & 0.41 \\
\hline
\end{tabular}

\section{Discussion}

Larvae of the species belonging to the subgenus $M i$ cruracarus have at least three pectinate setae on PV (Zawal 2006b). The characters differentiating the species described include: the number of pectinate setae on $\mathrm{PV}$, the shape of the dorsal and excretory pore plates; and the proportions of $\mathrm{CpI} / \mathrm{CpII} / \mathrm{CpIII}$. A. biscissus shows four pectinate setae (PV4, PV5, PV7 and PV8), three pectinate setae each occurring in A. pugionifer and A. bisulcicodulus (PV5, PV7 and PV8). The A. biscissus larva is very similar to that of $A$. sinuator in shape of dorsal plate, $\mathrm{CpI} / \mathrm{CpII} / \mathrm{CpIII}$ ratio, in shape of chelicera, in the size and pectinating of the PIII1, PV4 and PV5 setae, and in the size and setation of legs; which characters differ them from other Arrenurus species (Zawal 2006b). A. biscissus larva differs from $A$. sinuator in having a more rounded posterior margin to the dorsal plate, in the shape of Exp which is rhomboid with a small process on the posterior margin in $\mathrm{A}$. $\mathrm{si}$ nuator and pentagonal with a much larger process in $A$. biscissus, and in the PV4 and PV5 setae, which are pectinate along the entire length in A. biscisus, while in $A$. sinuator they begin to be pectinate at $1 / 3$ of their length from the base. The A. biscissus larvae are slightly larger than those of $A$. sinuator. However, because all the dimensions are proportionally larger and the number of $A$. biscisus larvae obtained from the culture was relatively low, the existence of smaller A. biscissus larvae cannot be ruled out. Imagines of the two species are very similar also, which evidences their close affinity.

Larvae of A. pugionifer and A. bisulcicodulus reseamble in particular characters to different Arrenurus species. Therefore we are can not to show the most similar species. In their proportions of $\mathrm{CpI} / \mathrm{CpII} / \mathrm{CpIII}$ and presence secondary setae on the three PV setae, the A. pugionifer and A. bisulcicodulus larvae resemble the larvae of three other species (A. bifidicodulus, A. inexploratus, A. integrator) of the sub-genus Micruracarus (other species of Micruracarus have more then three PV setae pectinate) (Zawal 2006b, 2007).

Dorsal plates and excretory pore plates in the Micruracarus larvae have differ shape in different species (Zawal 2006b) and cannot be used as a diagnostic character of subgenus Micruracarus. The dorsal plate of $A$. pugionifer is similar to that of $A$. stecki, a species representing the sub-genus Truncaturus (Zawal 2006e), while the dorsal plate of A. bisulcicodulus resembles those of the species (A. tricuspidator, A. claviger) belonging to the sub-genus Arrenurus s. str. (Zawal 2006d, c). The Expp of $A$. bisulcicodulus resembles than in $A$. inexploratus (Zawal 2007), while the Expp of A.pugionifer is similar to that in A. sinuator (Zawal 2006b).

Larvae of all the species described in this work show one character typical for larvae of the subgenus Micruracarus (at least three PV setae are pennate). From other points of view the A. biscissus larva is very 




Fig. 1. Morphology of the larva of Arrenurus biscissus: A - ventral side, B - dorsal plate, C - excretory pore plate, D - pedipalp, E - chelicera, F - leg I, G - leg II, H - leg III. 


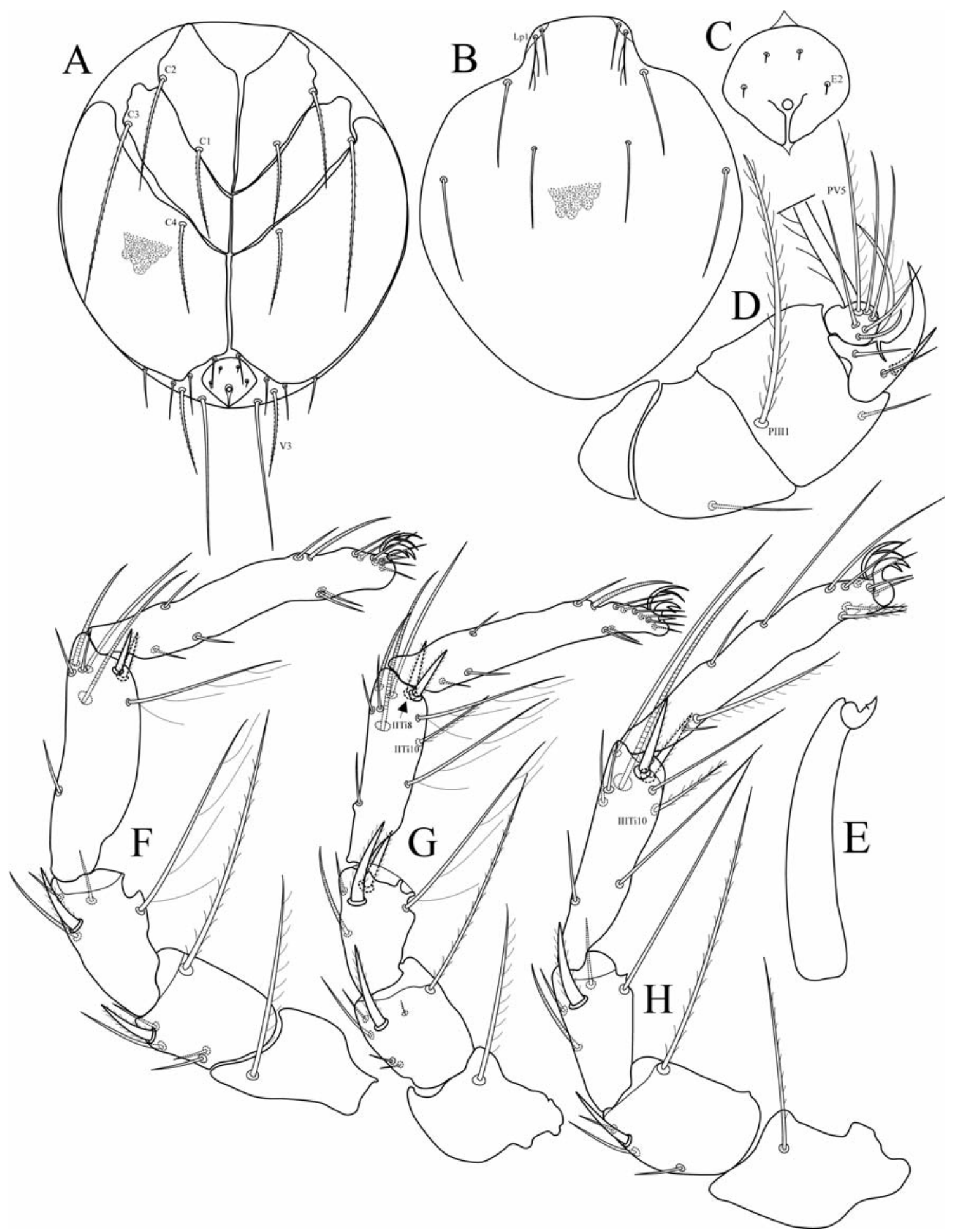

Fig. 2. Morphology of the larva of Arrenurus pugionifer: A - ventral side, B - dorsal plate, C - excretory pore plate, D - pedipalp, E - chelicera, F - leg I, G - leg II, H - leg III. 


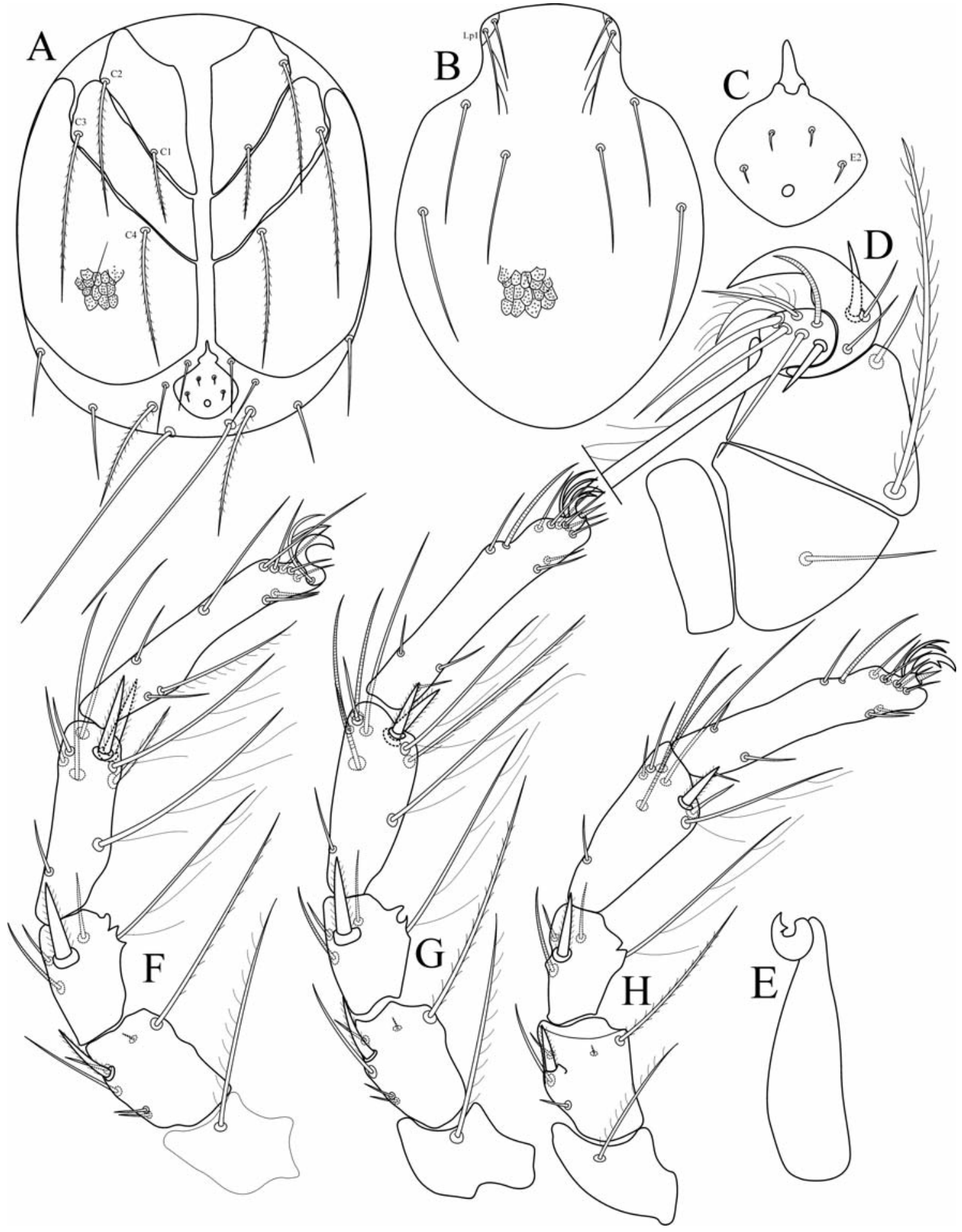

Fig. 3. Morphology of the larva of Arrenurus bisulcicodulus: A - ventral side, B - dorsal plate, C - excretory pore plate, D - pedipalp, E - chelicera, F - leg I, G - leg II, H - leg III. 
similar to that of the very closely related $A$. sinuator, while larvae of A. pugionifer and A. bisulcicodulus resemble to those of other subgenera (Truncaturus and Arrenurus s. str.). It seems that the analysis of larval morphology could serve as a starting point for phylogenetic conclusions, but these, however, would have to be based on analysis of larvae of a higher number of species representing the genus Arrenurus. Further studies with more species from all subgenera are need in order to test if the characters investigated here are useful for definition of species-groups and subgenera in Arrenurus.

\section{Acknowledgements}

I thank E. Biesiadka, University of Warmia and Mazury for consultation, and R. A. Baker, University of Leeds for corrections to the text. Financial support was provided by the Committee for Scientific Research in 2004-2007 years, research grant no. 2P04C10527.

\section{References}

Böttger K. \& Martin P. 2003. - On the morphfology and parasitism of Arrenurus globator (O.F. Müller, 1776) (Hydrachnidia, Acari) a water mite with an unusually extensive host spectrum. Acarologia, 43, 49-57.

Cichocka M. 1980. - Opis larwy Arrenurus bifidicodulus Piersig, 1897 (Hydrachnellae, Acari). Przegl.Zool., 24, 309-315. [in Polish with English summary]

Cook D.R. 1974. - Water mite genera and subgenera. Mem. Am. ent. Inst., 21, 1-860.

Imamura T. \& Mitchell R. 1967. - The water mites parasitic on the damselfly, Cercion hierglyphicum Brauer. I. Systematics and life history. Annot. Zool. Japan., 40, 28-36.

Koenike F. 1908. - Beitrag zur Kenntnis der Hydrachniden. Abh. naturw. Ver., Bremen, 19, 245-250.

Lundblad O. 1927. - Die Hydracarinen Schwedens. I. Beitrag zur Systematik, Embryologie, Ökologie und Verbreitungsgeschichte der schwedischen. Arten. Zool. Bidrag, 11, 185-540.

Lundblad O. 1930. - Hydracarina. Zoology of the Faroes Copenhagen, 2, 1-65.
Martin P. 2000. - Larval morphology and host-parasite associations of some stream living water mites (Hydrachnidia, Acari). Arch. Hydrobiol., suppl., 121(3-4), 269-320.

Münchberg P. 1936. - Zur Morphologie der Arrenurus- und Georgella-Larven nebst -Nymphen, mit besonderer Berücksichtigung der Libellenparasiten. Arch. Naturg. N. F., 5, 93-115.

Prasad V. \& Cook. D.R. 1972. - The taxonomy of water mite larvae. Mem. Am. ent. Inst., 18, 1-326

Smith B.P. 1990. - Description of larval Arrenurus bartonensis Cook, Arrenurus birgei Marshall, Arrenurus neobirgei Cook, and Arrenurus rotundus Marshall (Acari: Hydrachnidia; Arrenuridae). Can. Ent., 122, 77-91.

Smith I.M. 1978. - Descriptions and observations on host associations of some larval Arrenuroidea (Prostigmata: Parasitengona), with comments on phylogeny in the superfamily. Can. Ent., 110, 957-1001.

Smith I.M. \& Cook D.R. 1991. - Water mites. In: Thorp, J. H. \& Covich, A. P. (eds) Ecology and Classification of North American Freshwater Invertebrates (New York: Academic Press), 523-592.

Sparing J. 1959. - Die Larven der Hydrachnellae, ihre parasitische Entwicklung und ihre Systematik. Parasit. Schr. reiche, 10, 1-168.

Tuzovsky P.V. 1987. - Morphologia i postembrionalnoie raswitie wodianych klieščiej. Nauka, Moscow, 172 p. [in Russian]

Vainstein B.A. 1980. - Opriedielitiel ličinok wodianych klieščiej. Nauka, Leningrad, 238 p. [in Russian]

Zawal A. 2006a. - Morphology of larval stages of Arrenurus cuspidator (O. F. Müller, 1776), and A. maculator (O. F. Müller, 1776) (Acari: Hydrachnidia). Zootaxa, 1194, 57-68.

Zawal A. 2006b. - Morphology of the larvae of three species of Arrenurus (Acari: Parasitengona: Arrenuridae). Jour. Nat. Hist., 40 (1-2), 89-100.

Zawal A. 2006c. - Larval morphology of Arrenurus cuspidifer Piersig, A. claviger Koenike, and A. latus Barrois \& Moniez (Acari: Hydrachnidia). Zootaxa, 1276, 55-68.

Zawal A. 2006d. - Morphology of the larval stages of Arrenurus bicuspidator Berlese, 1885; A. tricuspidator (O.F. Müller), 1776 and A. tetracyphus Piersig, 1894. Acarina, 14 (1), 89-96.

Zawal A. 2006e. - Morphology of the larvae of Arrenurus nodosus Koenike, 1896; A. knauthei Koenike,1895 and A. stecki Koenike, 1894 (Acari: Parasitengona: Arrenuridae). Ann. Limnol. -Int. J. Lim., 42 (3), 197-204.

Zawal A. 2007. - Morphology of larval stages of Arrenurus crassicaudatus Kramer, 1875; A. inexploratus Viets, 1930 and A. integrator (O. F. Müller), 1776. Acarologia. (in press). 